\title{
Optimasi Metode Particle Swarm Optimization (PSO) Pada Prediksi Penilaian Apartemen
}

\author{
Lala Nilawati', Yuni Eka Achyani² \\ ${ }^{1}$ Universitas Bina Sarana Informatika \\ e-mail: lala.lni@bsi.ac.id
}

${ }^{2}$ Sekolah Tinggi Manajemen Informatika dan Komputer Nusa Mandiri e-mail: yuni.yea@nusamandiri.ac.id

\begin{abstract}
Cara Sitasi: Nilawati, L., \& Achyani, Y. E. (2019). Optimasi Metode Particle Swarm Optimization (PSO) Pada Prediksi Penilaian Apartemen. Paradigma - Jurnal Komputer dan Informatika, 21(2), $227-234$. doi:10.31294/p.v21i2.6159
\end{abstract}

\begin{abstract}
One property that is currently being glimpsed by investors is an apartment. Property consulting companies as one of the service provider companies that become a link between apartment owners and apartment enthusiasts, have an important task in terms of providing information about the assessment of the offered institutions. This study will conduct a trial on the accuracy of apartment assessment predictions using the Support Vector Machine (SVM) method, then will be compared again with the results of the accuracy of the assessment method Support Vector Machine (SVM) combined using the optimization method Particle Swarm Optimization (PSO). The results of the combination of the application of SVM and PSO are used to optimize attribute selection in apartment valuation to improve the accuracy of using the SVM method. This study shows that the Particle Swarm Optimization (PSO) Support Vector Machine (SVM) method is a pretty good method of data classification, because it can seen from the increase in accuracy of $2.84 \%$ and AUC of 0.003. Subjects (attributes) that affect apartment valuation are seen from rent prices (price range), city (apartment location), size (area), furnisihing (equipment), bedroom (number of bedrooms), bathroom (number of bathrooms) and maids badroom (number of maid rooms). The results of the attribute testing showed that city attributes (apartment locations), furnisihing (equipment) and maid badroom (number of maid rooms) greatly influenced the valuation of an apartment.
\end{abstract}

Keywords: Support Vector Machine (SVM), Particle Swarm Optimization (PSO), Apartment Rating

\section{PENDAHULUAN}

Apartemen merupakan salah satu jenis properti yang saat ini banyak dilirik oleh para investor, sehingga banyak para perusahaan konsultan properti berlombalomba dalam menawarkan apartemen yang terbaik yang dimiliki. Perusahaan konsultan properti selalu melakukan penilaian untuk semua jenis properti yang ditawarkan, tidak terkecuali jenis apartemen. Menurut Arikunto menyebutkan bahwa "Penilaian adalah mengambil suatu keputusan terhadap sesuatu dengan ukuran baik buruk dan penilaian bersifat kualitatif" (Arikunto, 2009). Salah satu faktor untuk mengetahui nilai pasar apartemen bisa dilihat melalui pendekatan sales comparison approach (pendekatan data pasar). Pendekatan sales comparison approach (pendekatan data pasar) adalah salah satu pendekatan yang banyak digunakan dalam penilaian properti karena mudah digunakan dan data yang diperoleh berasal langsung dari pasar (Janssen, 2003). Teknik regresi adalah salah satu teknik yang digunakan dalam mengurangi subjektifitas pada pendekatan sales comparison approach, teknik ini menentukan faktor-faktor fisik yang mempengaruhi nilai pasar apartemen yaitu lokasi, fasilitas dan fisik bangunan apartemen (Betts \& Elly, 2001). Irooth dan Anstasia dalam penelitian mengenai penilaian apartemen di Surabaya menyimpulkan bahwa variabel view taman, view golf, jumlah kamar, luas, akses ke pusat perbelanjaan, akses ke rumah sakit, akses ke sekolah, dan akses ke tempat kerja berpengaruh pada nilai apartemen (Irooth \& Anastasia, 2017). Pada penelitian ini subjek-subjek (atribut) yang mempengaruhi penilaian apartemen dilihat dari rent price (range harga), city (lokasi apartemen), size (luas), furnisihing (perlengkapan), bedroom (jumlah kamar tidur), bathroom (jumlah kamar mandi) dan maid badroom (jumlah kamar pembantu). Prediksi penilaian apartemen ini akan diuji lewat perbandingan hasil akurasi penilaian, yang diperoleh menggunakan metode Support Vector Machine (SVM), kemudian akan dibandingkan lagi dengan hasil akurasi penilaian metode Support Vector Machine (SVM) yang dikombinasikan mengggunakan optimasi metode Particle Swarm Optimization (PSO). Hasil kombinasi penerapan 
SVM dan PSO digunakan untuk optimasi seleksi atribut dalam penilaian apartemen untuk meningkatkan akurasi penggunaan metode SVM.

Pada penelitian yang dilakukan oleh Jun, dkk menggabungkan algoritma CART dan Particle Swarm Optimization (PSO) adaftif sebagai alat optimasi yang memungkinkan bisa menjadi alternatif yang baik, dalam mengoptimalkan aturan klasifikasi berbasis pohon keputusan (Jun, Cho, \& Lee, 2013). Algortima C45 yang berbasis PSO sudah diuji dan memperoleh akurasi yang paling tinggi, dengan nilai akurasi mencapai $89.09 \%$ dalam prediksi untuk pencapaian hapalan Al-Qur'an di Pesantren Tahfizh Daarul Qur'an (Muchlis \& Pahlevi, 2018). Penggunaan Support Vector Machine berbasis Particle Swarm Optimization untuk data yang terkait kampanye pemasaran langsung, dari lembaga perbankan Portugis yang diperoleh dari UCI Repository tahun 2012, didapat nilai akurasi sebesar $89,38 \%$ dan ini membuktikan ada kenaikan nilai akurasi dari yang sebelumnya sebesar $88,71 \%$ dibandingkan dengan metode Support Vector Machine tunggal (Achyani, 2018). Penelitian Noor dalam memprediksi siswa bermasalah, menggunakan perbandingkan algoritma $\mathrm{C} 4.5$ dengan $\mathrm{C} 4.5$ berbasis PSO (Particle Swarm Optimazion) menunjukan bahwa kombinasi $\mathrm{C} 4.5$ dan Particle Swarm Optimization menjadi lebih baik dalam memprediksi nilai akurasi daripada menggunakan hanya metode C4.5 saja, yang mampu meningkatkan nilai akurasi cukup tinggi yaitu sebesar $35.7 \%$ (Noor, 2018). Particle Swarm Optimization (PSO) dikombinasikan dengan algoritma Nä̈ve Bayes dalam memprediksi kredit macet pada koperasi memberikan nilai akurasi sebesar $89 \%$ dengan diagnosa klasifikasi baik (good classification). Performansi kinerja metode PSONaive Bayes dengan Sample Stratified menghasilkan peningkatan akurasi sebesar 21,03\% dan AUC sebesar 0,069 dibandingkan dengan metode Naive Bayes tunggal dan menjadi solusi pemecahan permasalahan dalam memprediksi kredit macet pada koperasi (Mardiana, 2018).

\section{Data Minning}

Data mining atau lebih di kenal juga dengan sebutan Knowledge Discovery in Databases (KDD) merupakan metode untuk memperoleh pengetahuan dari database yang ada. Istilah Knowledge Discovery in Database (KDD) dan data mining seringkali digunakan secara bergantian untuk menjelaskan proses penggalian informasi tersembunyi dalam suatu basis data yang besar. Sebenarnya kedua istilah tersebut memiliki konsep yang berbeda, tetapi berkaitan satu sama lain, dan salah satu tahapan dalam keseluruhan proses KDD adalah data mining (Bramer, 2007). Data mining dibagi menjadi beberapa kelompok berdasarkan tugas yang dapat dilakukan (Bramer, 2007), yaitu:

1. Description (Deskripsi)
Yaitu proses untuk menemukan suatu karakteristik penting dari data dalam suatu basis data. Deskripsi dari pola dan kecenderungan sering memberikan kemungkinan penjelasan untuk suatu pola atau kecenderungan. Tujuan dari Deskripsi adalah mengidentifikasi pola yang muncul secara berulang pada suatu data dan mengubah pola tersebut menjadi aturan/kriteria yang dapat mudah dimengerti.

2. Classification (Klasifikasi)

Dalam klasifikasi, terdapat target variabel kategori. Klasifikasi merupakan proses menemukan sebuah model atau fungsi yang mendeskripsikan dan membedakan data ke dalam kelas-kelas. Klasifikasi melibatkan proses pemeriksaan karakteristik dari objek dan memasukkan objek ke dalam salah satu kelas yang sudah didefinisikan sebelumnya.

3. Estimation (Estimasi)

Estimasi hampir sama dengan klasifikasi, kecuali variabel target estimasi lebih ke arah numerik daripada ke arah kategori. Model dibangun menggunakan record lengkap yang menyediakan nilai dari variabel target sebagai nilai prediksi. Selanjutnya, pada peninjauan berikutnya estimasi nilai dari variabel target dibuat berdasarkan nilai variabel prediksi.

\section{Prediction (Prediksi)}

Prediksi hampir sama dengan klasifikasi dan estimasi, kecuali bahwa dalam prediksi nilai dari hasil akan ada dimasa mendatang.

\section{Clustering (Pengklusteran)}

Pengklusteran merupakan pengelompokan yang memperhatikan dan membentuk kelas objek-objek yang memiliki kemiripan record atau pengamatan. Kluster adalah kumpulan record yang memiliki kemiripan satu dengan yang lainnya dan memiliki ketidakmiripan dengan record-record dalam kluster lain. Tujuannya adalah untuk menghasilkan pengelompokan objek yang mirip satu sama lain dalam kelompok-kelompok. Semakin besar kemiripan objek dalam suatu cluster dan semakin besar perbedaan tiap cluster maka kualitas analisis cluster semakin baik.

6. Association (Asosiasi)

Tugas asosiasi dalam data mining adalah menemukan atribut yang muncul dalam satu waktu. Dalam dunia bisnis lebih umum disebut analisis keranjang belanja. Tugas asosiasi berusaha untuk mengungkap aturan untuk mengukur hubungan antara dua atau lebih atribut.

\section{K-Fold Cross Validation}

Cross Validation (CV) adalah salah satu metode statistik yang digunakan dengan tujuan untuk mengevaluasi kinerja model atau algoritma, dimana data dipisahkan menjadi dua data subset yaitu data proses pembelajaran dan data validasi/evaluasi (Witten, Frank, \& Hall, 2011). Jenis Cross Validation (CV)-K Fold dapat dipilih berdasarkan pada ukuran dataset, dan biasanya digunakan karena dapat mengurangi waktu komputasi dengan tetap menjaga keakuratan estimasi. Cross Validation (CV) hal 
utamanya dapat digunakan untuk melakukan prediksi model dan memperkirakan seberapa akurat sebuah model prediktif ketika dijalankan dalam praktiknya. Pada permasalahan prediksi sebuah model biasanya diberikan dataset yang nantinya digunakan dalam menjalankan pelatihan (dataset pelatihan), serta kumpulan data yang tidak diketahui (atau data yang pertama kali dilihat) terhadap model yang diuji (pengujian dataset). Metode 3-Fold Cross Validation (CV) membagi sebuah himpunan secara acak menjadi tiga subset yang saling bebas. Cara kerja metode ini akan melakukan pengulangan sebanyak tiga kali untuk pelatihan dan pengujian. Pada setiap ulangan, disisakan satu subset untuk pengujian dan subset lainnya untuk pelatihan. Tingkat akurasi dihitung dengan membagi jumlah keseluruhan klasifikasi yang benar dengan jumlah semua instance pada data awal.

\section{Support Vector Machine (SVM)}

Support Vector Machine (SVM) dikenal juga dengan support vector network yang merupakan metode supervised terkait dengan learning algorithm untuk analisa pola data yang digunakan untuk klasifikasi dan regresi (Khan, Badruddin, \& Bashier, 2007). SVM merupakan usaha mencari hyperplane terbaik yang berfungsi sebagai pemisah dua buah class pada input space (Nugroho, Witarto, \& Handoko, 2003). SVM saat pertama kali diperkenalkan oleh Vapnik pada tahun 1992, hanya dapat mengklasifikasikan data ke dalam dua kelas (klasifikasi biner). Secara prinsip SVM adalah linear classifier bidang dalam komputer sains, yang memetakan suatu data ke dalam konsep tertentu yang telah didefinisikan sebelumnya (Pattern Recognition) (Nugroho et al., 2003). Aplikasi pattern recognition sangat luas, di antaranya mengenali suara dalam sistem sekuriti, membaca huruf dalam OCR, mengklasifikasikan penyakit secara otomatis berdasarkan hasil diagnosa kondisi medis pasien dan sebagainya. Pattern recognition dilakukan dengan mentransformasikan data pada input space ke ruang yang berdimensi lebih tinggi, dan optimisasi dilakukan pada ruang vector yang baru tersebut. Hal ini membedakan SVM dari solusi pattern recognition pada umumnya, yang melakukan optimisasi parameter pada ruang hasil transformasi yang berdimensi lebih rendah daripada dimensi input space. SVM menerapkan strategi Structural Risk Minimization (SRM) yang bertujuan menemukan hyperplane terbaik yang memisahkan dua buah class pada input space. Beberapa kelebihan SVM dapat dilihat sebagai berikut:

1. Generalisasi

Yaitu kemampuan suatu metode (SVM, neural network, dsb.) untuk mengklasifikasikan suatu pattern, yang tidak termasuk data yang dipakai dalam fase pembelajaran metode itu. Strategi pembelajaran pada SVM meminimalkan error pada training-set, juga meminimalkan faktor kedua. Strategi ini disebut Structural Risk Minimization (SRM), dan dalam SVM diwujudkan dengan memilih hyperplane dengan margin terbesar. Berbagai studi empiris menunjukkan bahwa pendekatan SRM pada SVM memberikan error generalisasi yang lebih kecil daripada yang diperoleh dari strategi ERM pada neural network maupun metode yang lain.

\section{Curse of dimensionality}

Didefinisikan sebagai masalah yang dihadapi suatu metode pattern recognition dalam mengestimasikan parameter. Curse of dimensionality sering dialami dalam aplikasi di bidang biomedical engineering, karena biasanya data biologi yang tersedia sangat terbatas, dan penyediaannya memerlukan biaya tinggi. SVM merupakan salah satu metode yang tepat dipakai untuk memecahkan masalah berdimensi tinggi, dalam keterbatasan sampel data yang ada (Vapnik, 1999).

3. Landasan teori

SVM memiliki landasan teori yang dapat dianalisa dengan jelas, dan tidak bersifat black box.

4. Feasibility

SVM dapat diimplementasikan relatif mudah, karena proses penentuan support vector dapat dirumuskan dalam QP problem. Jika kita memiliki library untuk menyelesaikan QP problem, dengan sendirinya SVM dapat diimplementasikan dengan mudah.

Untuk kelemahan nya bisa dilihat jika SVM Sulit dipakai dalam problem berskala besar. Skala besar dalam hal ini dimaksudkan dengan jumlah sample yang diolah. Selain itu walaupun SVM telah dimodifikasi agar dapat menyelesaikan masalah dengan class lebih dari dua, antara lain strategi One versus rest dan strategi Tree Structure, tetapi masingmasing strategi ini memiliki kelemahan dan perlu pengembangan lebih lanjut.

\section{Particle Swarm Optimization (PSO)}

Metode PSO diperkenalkan oleh Dokter Kennedy dan Elbert pada tahun 1995 berdasarkan penelitian yang dilakukan terhadap prilaku kawanan burung dan ikan dan merupakan metode optimasi heuristic global (Bai, 2010). PSO adalah algoritma iteratif berbasis populasi. Populasi terdiri dari banyak partikel, di mana diinisialisasi dengan populasi solusi acak dan digunakan untuk memecahkan masalah optimasi (Abraham, Grosan, \& Ramos, 2006). Setiap partikel mewakili solusi kandidat dan bergerak menuju posisi optimal dengan mengubah posisinya sesuai dengan kecepatan partikel terbang melalui ruang pencarian dengan kecepatan yang dinamis disesuaikan untuk perilaku historis. Oleh karena itu, partikel memiliki kecenderungan untuk terbang menuju daerah pencarian yang lebih baik dan lebih baik selama proses pencarian (Abraham et al., 2006). Rumus untuk menghitung perpindahan posisi dan kecepatan partikel yaitu:

$$
\begin{aligned}
& V_{i}(t)=V_{i}(t-1)+c_{1} r_{1}\left[X_{p b e s t i}-X_{i}(t)\right]+c_{2} r_{2}\left[X_{\text {gbest }}-X_{i}(t)\right] \ldots .(1) \\
& X_{i}(t)=X_{i}(t-1)+V_{i}(t) \ldots \ldots \ldots \ldots \ldots \ldots \ldots \ldots \ldots \ldots \ldots \ldots \ldots \ldots \ldots \ldots \ldots \ldots \ldots \ldots \ldots \ldots
\end{aligned}
$$

Dimana:

$V_{i}(t)=$ kecepatan partikel i saat iterasi $\mathrm{t}$

$X_{i}(t)=$ posisi partikel i saat iterasi $\mathrm{t}$ 
$\mathrm{c}_{1}$ dan $\mathrm{c}_{2}=$ learning rates untuk kemampuan individu (cognitive) dan pengaruh sosial (group)

$\mathrm{r}_{1}$ dan $\mathrm{r}_{2}=$ bilangan random yang berdistribusi uniformal dalam interval 0 dan 1

$X_{\text {pbest }}=$ posisi terbaik partikel $\mathrm{i}$

$X_{\text {gbest }}=$ posisi terbaik global

\section{Confusion matrix}

Confusion matrix digunakan untuk melakukan evaluasi terhadap model klasifikasi berdasarkan perhitungan objek testing yang ditabulasikan kedalam tabel dimana akan diprediksi benar dan tidak benar (Gorunescu, 2011). Confusion matrix merupakan data set hanya memiliki dua kelas, kelas

\begin{tabular}{|c|c|c|c|}
\hline CLASSIFICATION & \multicolumn{3}{|c|}{ PREDICTED CLASS } \\
\hline \multirow{3}{*}{ OBSERVED CLASS } & & Class = YES & Class $=\mathrm{N} 0$ \\
\hline & Class $=\mathrm{YES}$ & $\begin{array}{c}a \\
\text { (true positive-TP) }\end{array}$ & $\begin{array}{c}b \\
\text { (false negative }-\mathrm{FN} \text { ) }\end{array}$ \\
\hline & Class $=\mathrm{NO}$ & $\begin{array}{c}c \\
\text { (false positive-FP) }\end{array}$ & $\begin{array}{c}d \\
\text { (true negative-TN) }\end{array}$ \\
\hline
\end{tabular}

yang satu sebagai positif dan kelas yang lain sebagai negatif. Terdiri dari empat sel yaitu True Positives (TP), False Positives (FP), True Negatives (TN) dan False Negatives (FN) (Bramer, 2007).

Gambar 1 Confusion matrix untuk 2 model kelas Sumber: (Gorunescu, 2011)

\section{Kurva ROC}

ROC mengekspresikan confusion matrix (Vercellis, 2009). Kurva ROC digunakan untuk menunjukan visualisasi dari akurasi model dan perbandingkan perbedaan antar model klasifikasi. ROC adalah grafik dua dimensi dengan false positives sebagai garis horizontal dan true positives untuk mengukur perbedaaan performasi metode yang digunakan. Kurva ROC adalah teknik untuk memvisualisasi dan menguji kinerja pengklasifikasian berdasarkan performanya (Gorunescu, 2011). Model klasifikasi yang lebih baik adalah yang mempunyai kurva ROC lebih besar (Vercellis, 2009). Performa keakurasian AUC dapat diklasifikasikan menjadi lima kelompok (Gorunescu, 2011) yaitu:
a. $0.90-1.00=$ Unggul
b. $0.80-0.90=$ Baik
c. $0.70-0.80=$ Cukup
d. $0.60-0.70=$ Kurang
e. $0.50-0.60=$ Gagal

\section{METODOLOGI PENELITIAN}

Data yang digunakan pada penelitian ini berasal dari perusahaan konsultan properti yang berlokasi di daerah kebayoran baru pada tahun 2015. Data yang akan diolah berupa data penilaian apartemen berjumlah 1727 record dan terdiri dari 7 atribut, dengan rincian 5 atribut bertipe numerik (Rent_Price, Size, Bedroom, Bathroom, dan Maid_Bathroom) dan
2 bertipe kategorikal (City dan Furnishing). Terdapat dua metode yang akan digunakan yaitu metode Support Vector Machine (SVM) dan metode Support Vector Machine (SVM) yang dikombinasikan dengan metode Particle Swarm Optimization (PSO). Untuk membandingkan atau mengkomparasi dalam penelitian ini akan menggunakan framework RapidMiner versi 5.3.1 sehingga akan ditemukan algoritma mana yang paling akurat.

Penelitian ini menggunakan metode penelitian eksperimen, yakni melibatkan penyelidikan perlakuan pada parameter atau variabel tergantung dari peneliti itu sendiri, dan menggunakan tes yang dikendalikan oleh si peneliti itu sendiri. Langkahlangkah yang dilakukan pada proses penelitian adalah sebagai berikut:

1. Pengumpulan Data

Ada dua tipe dalam pengumpulan data, yaitu pengumpulan data primer dan pengumpulan data sekunder. Data primer adalah data yang dikumpulkan pertama kali untuk melihat apa yang sesungguhnya terjadi. Sedangkan data sekunder adalah data yang sebelumnya pernah dibuat oleh seseorang baik diterbitkan atau tidak.

2. Pengolahan Data Awal

Pengolahan awal data meliputi proses input data ke format yang dibutuhkan, pengelompokan danpenentuan atribut data, serta pemecahan data (split) untuk digunakan dalam proses pembelajaran (training) dan pengujian (testing).

3. Model yang diusulkan

Pada tahap ini data dianalisis, kemudian dikelompokan variabel mana yang berhubungan dengan satu sama lainnya. Setelah data dianalisis lalu diterapkan model-model yang sesuai dengan jenis data. Pembagian data kedalam data latihan (training data) dan data uji (testing data) juga diperlukan untuk pembuatan model.

4. Eksperimen dan Pengujian Model

Pada bagian ini dijelaskan tentang langkahlangkah eksperimen meliputi cara pemilihan arsitektur yang tepat dari model atau metode yang diusulkan sehingga didapatkan hasil yang dapat membuktikan bahwa metode yang digunakan adalah tepat.

5. Evaluasi dan Validasi Hasil

Pada bagian ini dilakukan evaluasi dan validasi hasil penerapan terhadap model penelitian yang dilakukan untuk mengetahui tingkat keakurasian model.

\section{HASIL DAN PEMBAHASAN}

\section{Hasil Eksperimen dan Pengujian Metode}

Berikut adalah gambar pengujian Algoritma Support Vector Machine (SVM) menggunakan metode K-Fold Cross Validation dengan menggunakan RapidMiner: 

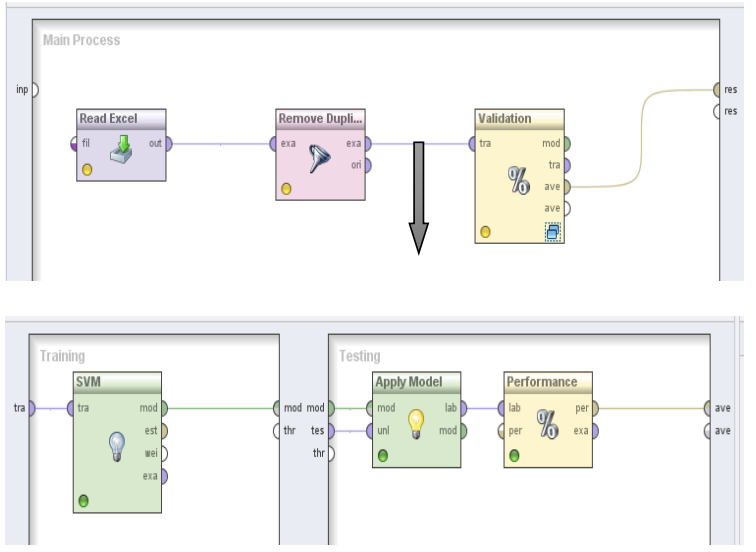

Sumber: Hasil Penelitian (2019)

Gambar 2. Pengujian K-Fold Cross Validation algoritma Support Vector Machine

Hasil terbaik pada eksperimen SVM diatas adalah $\mathrm{C}=0.0$ dan Epsilon=0.0 dihasilkan accuracy $79.20 \%$ dan AUC 0.770. Lalu diikuti SVM dengan $C=1.0$ dan Epsilon $=0.0$ dihasilkan accuracy $78.16 \%$ dan AUC 0.770, kemudian SVM dengan $\mathrm{C}=1.0$ dan Epsilon=1.0 dihasilkan accuracy $73.42 \%$ dan AUC 0.500.

Berikut adalah gambar pengujian algoritma support vector machine (SVM) berbasis Particle Swarm Optimization (PSO) menggunakan metode $K$ Fold Cross Validation dengan menggunakan RapidMiner.
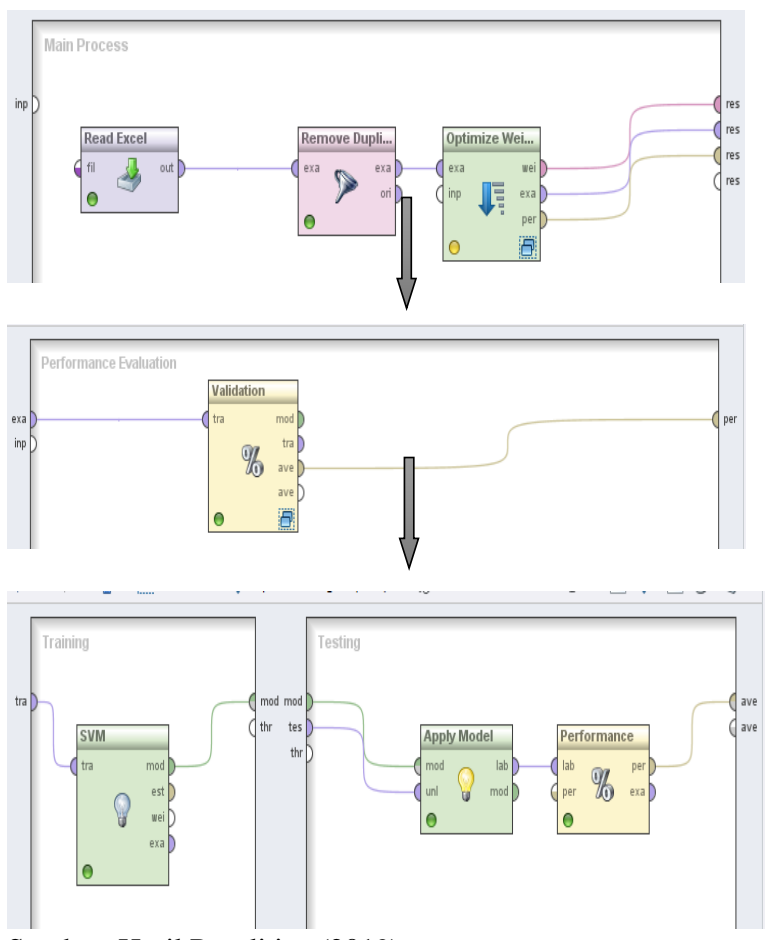

Sumber: Hasil Penelitian (2019)

Gambar 3. Pengujian K-Fold Cross Validation algoritma Support Vector Machine berbasis PSO

Nilai training cycles dalam penelitian ini ditentukan dengan cara melakukan uji coba memasukkan $\mathrm{C}$ dan epsilon. Selanjutnya dilakukan observasi terhadap variabel C dan $\varepsilon$ dari Support Vector Machine dan Particle Swarm Optimization. Berikut ini adalah hasil dari percobaan yang telah dilakukan untuk penentuan nilai training cycles.

Hasil terbaik pada eksperimen SVM berbasis PSO diatas adalah dengan $\mathrm{C}=0.0$ dan Epsilon=0.0 dihasilkan Accuracy sebesar 82.04\% dengan AUC sebesar 0.773 . Maka nilai-nilai tersebutlah yang akan digunakan pada penelitian ini.

\section{Evaluasi dan Validasi Model}

a. Hasil Pengujian Metode Support Vector Machine (SVM)

Gambar 4 menunjukkan hasil dari confusion matrix algoritma Support Vector Machine. Berdasarkan Gambar 3, dapat diketahui bahwa dari 1.787 data, 193 data diprediksi Good sesuai dengan prediksi yang dilakukan dengan metode SVM, kemudian 72 data di prediksi Good, tetapi ternyata hasil prediksinya adalah Best. Kemudian 1.467 data diprediksi Best, sesuai dengan prediksi yang dilakukan dengan metode SVM, dan 364 data diprediksi Best tetapi ternyata prediksinya Good.

\begin{tabular}{|c|c|c|c|}
\hline \multicolumn{4}{|c|}{ 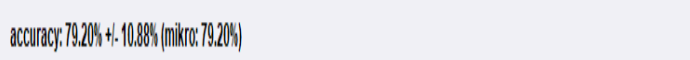 } \\
\hline & twe Good & twe Best & dass precision \\
\hline pred Good & 193 & 72 & 728336 \\
\hline pred Bess. & 364 & 1467 & $80.12 \%$ \\
\hline ddss5 pad & $34.65 \%$ & $95.32 \%$ & \\
\hline
\end{tabular}

Sumber: Hasil Penelitian (2019)

Gambar 4. Hasil Pengujian dengan Metode Support Vector Machine (SVM)

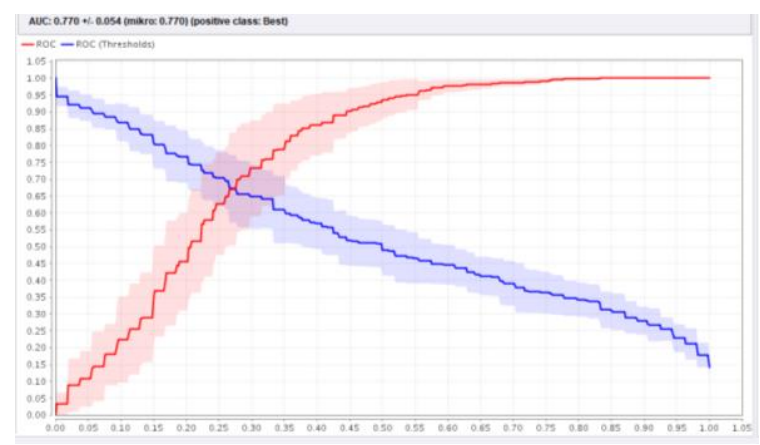

Sumber: Hasil Penelitian (2019)

Gambar 5. Kurva ROC

b. Hasil Pengujian Metode Support Vector Machine (SVM) berbasis Particle Swarm Optimization

Gambar 6 menunjukkan hasil dari confusion matrix algoritma Support Vector Machine berbasis Particle Swarm Optimization (PSO). Berdasarkan Gambar 5, dapat diketahui bahwa dari 
1.787 data, 272 data diprediksi Good sesuai dengan prediksi yang dilakukan dengan metode SVM, kemudian 56 data di prediksi Good, tetapi ternyata hasil prediksinya adalah Best. Kemudian 1194 data diprediksi Best, sesuai dengan prediksi yang dilakukan dengan metode SVM, dan 265 data diprediksi Best tetapi ternyata prediksinya Good.

\begin{tabular}{|c|c|c|c|}
\hline \multicolumn{4}{|c|}{ 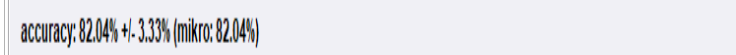 } \\
\hline & tre Good & true Best & dass precision \\
\hline pred Good & 272 & 56 & $8233 \%$ \\
\hline pred. Best & 265 & 1194 & $81.84 \%$ \\
\hline dass recall & $50.65 \%$ & $95.52 \%$ & \\
\hline
\end{tabular}

Sumber: Hasil Penelitian (2019)

Gambar 6. Hasil Pengujian dengan Metode Support Vector Machine (SVM) berbasis Particle Swarm Optimization (PSO)

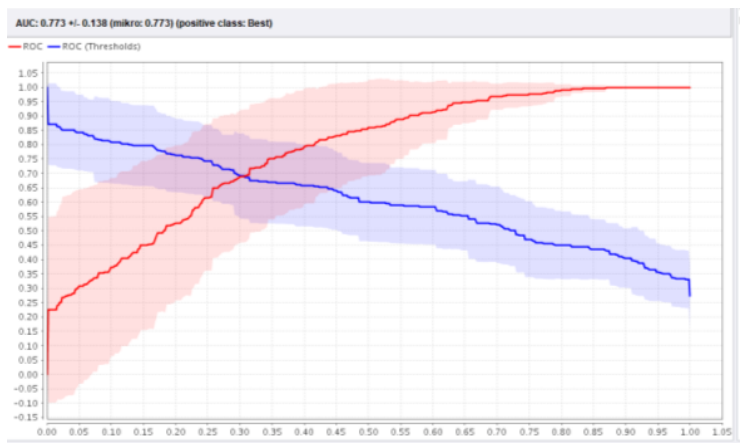

Sumber: Hasil Penelitian (2019)

Gambar 7. Kurva ROC

Hasil dari Atribute Weight yang didapat dari penelitian ini adalah sebagai berikut:

\begin{tabular}{|c|c|}
\hline & meght \\
\hline nil_sente & 0.716 \\
\hline cill_ota & 1 \\
\hline inlsice & 0.425 \\
\hline nilifunis & 1 \\
\hline inl beeroo & 0.884 \\
\hline rill bathr & 0.942 \\
\hline nil_maid & 1 \\
\hline
\end{tabular}

Sumber: Hasil Penelitian (2019)

Gambar 8. Attribute Weight dengan Algoritma SVM berbasis PSO

\section{Analisa Evaluasi dan Validasi Model}

Hasil Analisis dari metode Algoritma Support Vector Machine dan Support Vector Machine berbasis Particle Swarm Optimization dirangkum dalam tabel berikut:
Tabel 1. Komparasi Nilai Accuracy dan AUC

\begin{tabular}{|l|c|c|c|}
\hline & $\begin{array}{c}\text { Support } \\
\text { Vector } \\
\text { Machine }\end{array}$ & $\begin{array}{c}\text { SVM } \\
\text { Berbasis } \\
\text { PSO }\end{array}$ & Peningkatan \\
\hline Accuracy & $79.20 \%$ & $82.04 \%$ & $2.84 \%$ \\
\hline AUC & 0.770 & 0.773 & 0.003 \\
\hline
\end{tabular}

Pada Tabel 1 dapat dilihat bahwa nilai Accuracy dan AUC Algoritma Support Vector Machine berbasis Particle Swarm Optimization lebih tinggi dibandingkan dengan penggunaan SVM tunggal. Penerapan Algoritma Particle Swarm Optimization itu sendiri menghasilkan peningkatan akurasi sebesar 2.84 $\%$ dan AUC sebesar 0.003 .

Mengingat pentingnya seleksi atribut dalam Support Vector Machine (SVM) maka diterapkan Particle swarm optimization (PSO) untuk melakukan tugas tersebut. Particle Swarm Optimization (PSO) diketahui dapat digunakan sebagai teknik optimasi untuk mengoptimalkan subset fitur. Algoritma PSO sederhana dan memiliki kompleksitas yang lebih rendah. sehingga dapat memastikan solusi optimal dengan menyesuaikan pencarian global dan lokal, sehingga kinerja klasifikasi Support Vector Machine (SVM) dapat ditingkatkan. Eksperiment dilakukan kembali dengan menerapkan Particle swarm optimization (PSO) untuk seleksi atribut dalam Support Vector Machine (SVM) dan dilakukan penyesuaian pada parameter $\mathrm{C}$ dan $\varepsilon$. Dari 7 variabel predictor yaitu rent price (range harga), city (lokasi apartemen), size (luas), furnisihing (perlengkapan), bedroom (jumlah kamar tidur), bathroom (jumlah kamar mandi) dan maid badroom (jumlah kamar pembantu) dilakukan seleksi atribut sehingga menghasikan terpilihnya 3 atribut yang digunakan dan sangat mempengaruhi penilaian sebuah apartemen yaitu city (lokasi apartemen), furnisihing (perlengkapan) dan maid badroom (jumlah kamar pembantu).

\section{KESIMPULAN}

Hasil dari penelitian ini mempunyai implikasi terhadap penilaian apartemen yakni meliputi implikasi terhadap aspek sistem penunjang keputusan penilaian apartemen, aspek manajerial, dan aspek terhadap penelitian-penelitian selanjutnya sebagai berikut:

1. Implikasi terhadap aspek sistem pendukung keputusan penilaian apartemen

penerapan Particle Swarm Optimization (PSO) untuk seleksi atribut dalam Support Vector Machine (SVM) yang dilakukan dengan penyesuaian pada parameter $\mathrm{C}$ dan $\varepsilon$ mampu menunjukkan aspek berupa atribut yang berpengaruh terhadap hasil dari prediksi penilaian 
apatemen. Dari hasil ini menunjukkan bahwa metode Support Vector Machine berbasis Particle Swarm Optimization merupakan metode yang cukup baik dalam pengklasifikasian data. Dengan demikian metode Support Vector Machine berbasis Particle swarm optimization dapat memberikan pemecahan permasalahan analisa penilaian prediksi penilaian apartemen dan dapat mendukung pengambilan keputusan serta pengembangan sistem informasi manajemen pada Perusahaan Konsultasi Properti.

2. Implikasi terhadap aspek manajerial

Berdasarkan hasil penelitian dapat diketahui bahwa metode Support Vector Machine berbasis Particle Swarm Optimization dapat mendukung pengambilan keputusan dan pengembangan sistem informasi manajemen pada Perusahaan Konsultasi Properti, untuk itu diperlukan peningkatan kemampuan manajerial dalam hal penilaian apartemen agar mampu membuat keputusan yang baik.

3. Implikasi terhadap penelitian-penelitian sebelumnya

Untuk mengetahui kehandalan metode, maka pada penelitian selanjutnya dapat dilakukan penggunaan data set lebih dari satu. Penelitian seperti ini dapat dikembangkan pada unit bisnis serupa atau yang lain. Pengembangan dapat dilakukan dengan pemilihan parameter menggunakan metode Genetic Algorithm untuk meningkatkan hasil optimasi. Penggunaan algoritma yang lain juga dapat digunakan misalkan dengan metode Neural Network, C4.5, $K$-Nearest Neighbor dan sebagainya.

\section{REFERENSI}

Abraham, A., Grosan, C., \& Ramos, V. (2006). Swarm Intelegence in Data Mining. London: Verlag Berlin Heidelberg, Springer.

Achyani, Y. E. (2018). Penerapan Metode Particle Swarm Optimization Pada Optimasi Prediksi Pemasaran Langsung. Jurnal Informatika, 5(1), 1-11. https://doi.org/10.31311/ji.v5i1.2736

Arikunto, S. (2009). Dasar-dasar Evaluasi Pendidikan (edisi revisi). Jakarta: Bumi Aksara.

Bai, Q. (2010). Analysis of Particle Swarm Optimization Algorithm. Computer Dan Informasi Science, 3(1).

Betts, R. ., \& Elly, J. . (2001). Basic Real Estate Appraisal Fifth Edition. New Jersey: PrenticeHall, Inc Saddle River.

Bramer, M. (2007). Principles of Data Mining. London: Springer.

Gorunescu, F. (2011). Data Mining: Concepts and Techniques. Verlag berlin Heidelberg: Springer.
Irooth, A. M., \& Anastasia, N. (2017). Model Nilai Pasar Apartemen dan Kesedian Membayar View Apartemen di Surabaya. MAPPI Insight, 1(1), 35-40.

Janssen, C. T. . (2003). A Market Comparison Approach for Apartment Buildings. The Canadian Appraiser, 47(2), 32-37.

Jun, C. H., Cho, Y. J., \& Lee, H. (2013). Improving Tree-Based Classification Rules Using a Particle Swarm Optimization. IFIP Advances in Information and Communication Technology, 398(PART 2), 9-16. https://doi.org/10.1007/978-3-642-40361-3_2

Khan, M. M., Badruddin, M., \& Bashier. (2007). Machine Learning: Algorithms and Applications. New York: CRC Press.

Mardiana, T. (2018). Optimasi Naïve Bayes Dengan Particle Swarm Optimization. Jurnal Riset Informatika, 1(1), 43-50.

Muchlis, \& Pahlevi, S. M. (2018). Prediksi Pencapaian Hafalan Al-Qur'an Menggunakan Metode C4.5 Berbasis PSO. Seminar Nasional Sains Dan Teknologi 2018, 1-4.

Noor, H. (2018). Optimasi Model Klasifikasi C4.5 Dan Particle Swarm Optimization Untuk Prediksi Siswa Bermasalah. Technologia: Jurnal Ilmiah, 9(4), 228-237.

Nugroho, A. S., Witarto, A. B., \& Handoko, D. (2003). Suport Vector Machines: Teori Aplikasinya dalam Bioinformatika. ilmukomputer.com.

Vapnik, V. N. (1999). The Nature of Statistical Learning Theory (2 nd editi). New York Berlin Heidelberg: Springer-Verlag.

Vercellis, C. (2009). Business Intelligence: Data Mining and Optimization for Decision Making. Southern Gate, Chichester, West Sussex: John Willey \& Sons, Ltd.

Witten, I. H., Frank, E., \& Hall, M. A. (2011). Data Mining: Practical Machine Learning and Tools. Burlington: Morgan Kaufmann Publisher. 


\section{PROFIL PENULIS}

Lala Nilawati, M.Kom. Menempuh pendidikan Sarjana (S1) di Sekolah Tinggi Manajemen Informatika dan Komputer Nusa Mandiri, Program Studi Sistem Informasi lulus tahun 2010, dan Program Magister (S2) Sekolah Tinggi Manajemen Informatika dan Komputer Nusa Mandiri, Program Studi Ilmu Komputer lulus tahun 2015. Pernah bekerja menjadi Asisten Laboratorium Komputer Bina Sarana Informatika tahun 2006 sampai tahun 2007, tahun 2008 sampai sekarang aktif bekerja menjadi staff pengajar (dosen) di Universitas Bina Sarana Informatika program studi Sistem Informasi.
Yuni Eka Achyani, S.Kom. Tahun 2014 lulus dari Program Strata Satu (S1) Program Studi Sistem Informasi Sekolah Tinggi Manajemen Informatika dan Komputer Nusa Mandiri Nusa Mandiri dan Tahun 2016 lulus dari Program Magister (S2) Sekolah Tinggi Manajemen Informatika dan Komputer Nusa Mandiri. Saat ini bekerja sebagai Staff Pengajar (Dosen) di Sekolah Tinggi Manajemen Informatika dan Komputer Nusa Mandiri. 